\title{
Non-Invasive Endoscopy Technique - Virtual Colonoscopy
}

\author{
Baki Ekçi ${ }^{1}$, Bengi Gürses² and Düzgün Yıldırım³ \\ ${ }^{1}$ Yeditepe University Hospital, Department of General Surgery \\ ${ }^{2}$ Yeditepe University Hospital, Department of Radiology \\ ${ }^{3}$ Kasımpaşa Military Hospital, Department of Radiology, \\ Turkey
}

\section{Introduction}

Colorectal carcinoma ranks third in frequency among all cancers. With regards to cancer related mortality, colorectal carcinoma is known as the second cause (Levin et al., 2003). This condition accounts for $10 \%$ of all cancer related mortalities in women and men. Overall, lifetime risk for the development of colorectal carcinoma is still 5\%. (Eddy, 1990) The wellknown risk factors are age, inheritance, inflammatory bowel disease, and environmental and dietary factors. Despite these risk factors, any individual factors could not be demonstrated in $75-80 \%$ of cases. Nevertheless, it is reported that most of the colorectal cancers originate from polyps.

Colonic polyps are described as overgrowths of colonic mucosa regardless of histological findings (Van Dan, 1995). Vast majority of colorectal carcinomas originate from adenomatous polyps. This theory called adenoma-carcinoma sequence has been widely accepted (Hawk \& Levin, 2005). Colonic polyps are divided as: non-neoplastic, which has no risk or low risk of developing cancer (hamartomatous, inflammatory, hyperplastic); and neoplastic which has low risk of developing cancer (tubular adenoma, villous adenoma, tubulovillous adenoma). Histopathological analysis has an important place in the discrimination of polyps (Erdem et al., 2005; Netzer et al., 1998). The size of the polyps has an important role for the occurrence of invasive cancer (Altiparmak et al., 2001). Small polyps with size less than $1 \mathrm{~cm}$ have a low rate of developing invasive cancer. However, this rate increases, as the polyps get larger (Su et al., 2005; Yamaji et al., 2004). Colonic polyps are overgrowths with a slow progress that carry a small risk of malignant transformation. However, colonic polyps constitute an important predisposition to colon cancer, and therefore these neoplasms should be removed when detected.

Understanding the fact that development of colorectal carcinoma starts with mucosal lesions, the visualization of colon, early diagnosis of the lesions and the initiation of treatment have gained much importance. The determination of precancerous adenomatous polyps and cancer at an early stage with screening reduces mortality and morbidity associated with colon cancer (Chao et al., 2004; Van Dan, 1995). Thus, American Cancer Association emphasized the importance of screening in colon cancer (Jemal et al., 2002). It is possible to detect and treat polyps at a very early stage with various screening methods. This feature different from some other types of cancer enables prevention or early 
management of colorectal cancer (Eddy, 1990; Towler et al., 1998). Colonoscopy is the gold standard in the diagnosis of colorectal polyps (Roberts-Thomson et al., 2008). The most important advantage of this method is that it may also be used for treatment while being used in diagnosis. However, conventional colonoscopy has a serious complication risk of perforation, even if this risk is less than $1 \%$. If any intervention was performed, the complication rate may increase up to 5\%. (Consolo et al., 2008; Waye et al., 1992)

\section{Virtual colonoscopy}

In the last few years, the early diagnosis and cure rates of this condition is rather increased with the aid of screening methods. Digital rectal examination, occult blood test in stool, flexible sigmoidoscopy, double contrast barium enema and colonoscopy are among the routine screening methods of colorectal cancer. The American Cancer Society has included colorectal cancer screening in their guidelines. Screening the whole colon for colorectal cancer called as "total colon examination" is substantially emphasized in these guidelines. In association with this procedure, conventional colonoscopy, and double contrast barium enema are widely performed (Byers et al., 1997; Levin et al., 2003). Inadequate colon cleaning and air insufflations, and missing small polyps between the mucosal folds are among the limitations of double contrast barium enema. Flexible endoscopy has important advantages, such as high sensitivity in the diagnosis of colorectal polyps and opportunity of taking a biopsy (Chao et al., 2004; Colucci et al., 2003; Van Dam, 1995). It has taken the place of double contrast barium enema because of its superior efficiency. Despite its efficacy in the evaluation and treatment of colonic pathology, colonoscopy also has disadvantages such as being invasive, risk of perforation and hemorrhage, low patient tolerance, sedation requirement, perforation risk, and conditions in which the evaluation can not be properly finished (Anderson et al., 1992; Consolo et al., 2008; Detsky, 2001; Kim et al., 2007; White et al., 2009).

Patient intolerance is among the most important problems with the existing screening methods. With the technological developments in computed tomography (CT) systems, this problem has led the emergence of computed tomographic colonography (CTC) also termed as "virtual colonoscopy" technique (Hock et al., 2011). The American Cancer Society has described virtual colonoscopy as a promising screening technique in 1997 (Byers et al., 1997). Indeed, the idea of virtual colonoscopy has been initiated with the discovery of computed tomography (CT) by Godfrey Hounsfield in 1973 (Hounsfield, 1973). Following that, virtual colonoscopy was used in patients who cannot tolerate the conventional colonoscopy procedure. (Bakir et al., 2004; Ferrucci, 2001; Labianca \& Merelli, 2010; White et al., 2009). The positive results regarding patient tolerance with this minimally invasive technique confirmed this idea.

In the first step, two-dimensional (2D) high-resolution images in the axial plane are obtained with this screening technique. Then, three-dimensional (3D) images are constructed similar to conventional colonoscopy by digital software systems. After adequate colonic distention is ensured, CT examination is performed, preferentially with multi-detector systems. Data acquisition is performed first in the supine, and afterwards in the prone position. Imaging in two different positions, enables mobilization of the feces and fluid to the dependent wall and increases the accuracy of the CTC procedure. The multi-detector systems with higher resolution, significantly decreased scan time (within a single breath-hold) and thinner collimation have improved the sensitivity and specificity of CTC. Thin collimation is a must 
for an adequate CTC examination, in order to obtain high-quality three-dimensional images and multi-planar reformats. Another important point is that the scan should be completed in a single breath-hold period; otherwise motion artefacts might decrease the resolution (Pickhardt, 2007; Mang et al., 2007; Tolan et al., 2007; Wu et al., 2011)

\section{Preparation and technique}

Bowel cleansing and preparation is an important step of this procedure. There are a few recommendations for bowel cleansing. It is well known that adequate patient education and bowel preparation increase the sensitivity of this technique significantly. In the presence of an adequately cleansed bowel, the residual stool particles may result in false positive interpretation. Unlike colonoscopy, the residual fluid cannot be aspirated during the CTC examination. Therefore, the presence of fluid may cause in false negative results. Since the first introduction of CTC into the imaging practice, bowel preparation techniques have been changed and modified. Fecal and fluid tagging methods have been developed in addition to bowel cleansing, which have been shown to increase the accuracy of this examination (Taylor et al., 2003). Approximately $24-48$ hours before the examination, patients are informed to start a clear liquid diet. Bowel cleansing is generally performed using various agents such as sodium phosphate, polyethylene glycol, fleet enemas (phosphasoda) or magnesium citrate. In general, while phosphasoda is preferred in younger patients, polyethylene glycol is used in older age in order to avoid side effects (Bielen et al., 2003).

Adequate distention of the colon should be achieved for a high-quality CTC and accurate interpretation. In order to perform colonic distention, a rectal tube is inserted just before the examination. Prior to the rectal tube insertion, digital rectal examination should be performed and then the tube is inserted in the left decubitus position. Foley catheters and rectal tubes can be used for this purpose. It has been reported that catheters as thin as $20 \mathrm{~F}$ are adequate for optimal distention. The large caliber balloon rectal catheter is generally used in barium studies. However, it was not recommended due to the increased risk of colonic perforation. Both room air and $\mathrm{CO}_{2}$ are suitable to use during colonic insufflation. Using room air with a plastic handheld insufflator is practical and cost-effective and most centers use this method. On the other hand, some authors prefer the use of $\mathrm{CO}_{2}$, with the suggestion that it is rapidly absorbed from colonic mucosa with less post-procedure patient discomfort. The insufflation of $\mathrm{CO}_{2}$ or compressed air can be performed by manual means or automatically with an insufflator. The use of an insufflator enabling the control of both the intra-rectal pressure and the volume of gas delivered, is generally preferred because of its safety. The amount of gas delivered depends on the colonic length of the patient and the competency of ileocecal valve. After the insufflation is performed, a scout image of the abdomen is obtained, to evaluate the need for more insufflation. (Fig 1). During the insufflation process, antispasmodic agents may be administered to reduce the discomfort and spasms and to provide better distention. Yet, there is no consensus about the use of antispasmodic agents, and some authors disagree the use of these agents routinely, since they believe that administration of these agents increases the patients discomfort and may cause side effects. In most of the centers, antispasmolytics are not used routinely, but indicated when marked patient discomfort occurs (Bielen et al., 2003; Mang et al., 2007; Pickhardt et al 2003; Taylor et al., 2003; Tolan et al., 2007). After this procedure, the colonic pathway is determined (Fig 2) 


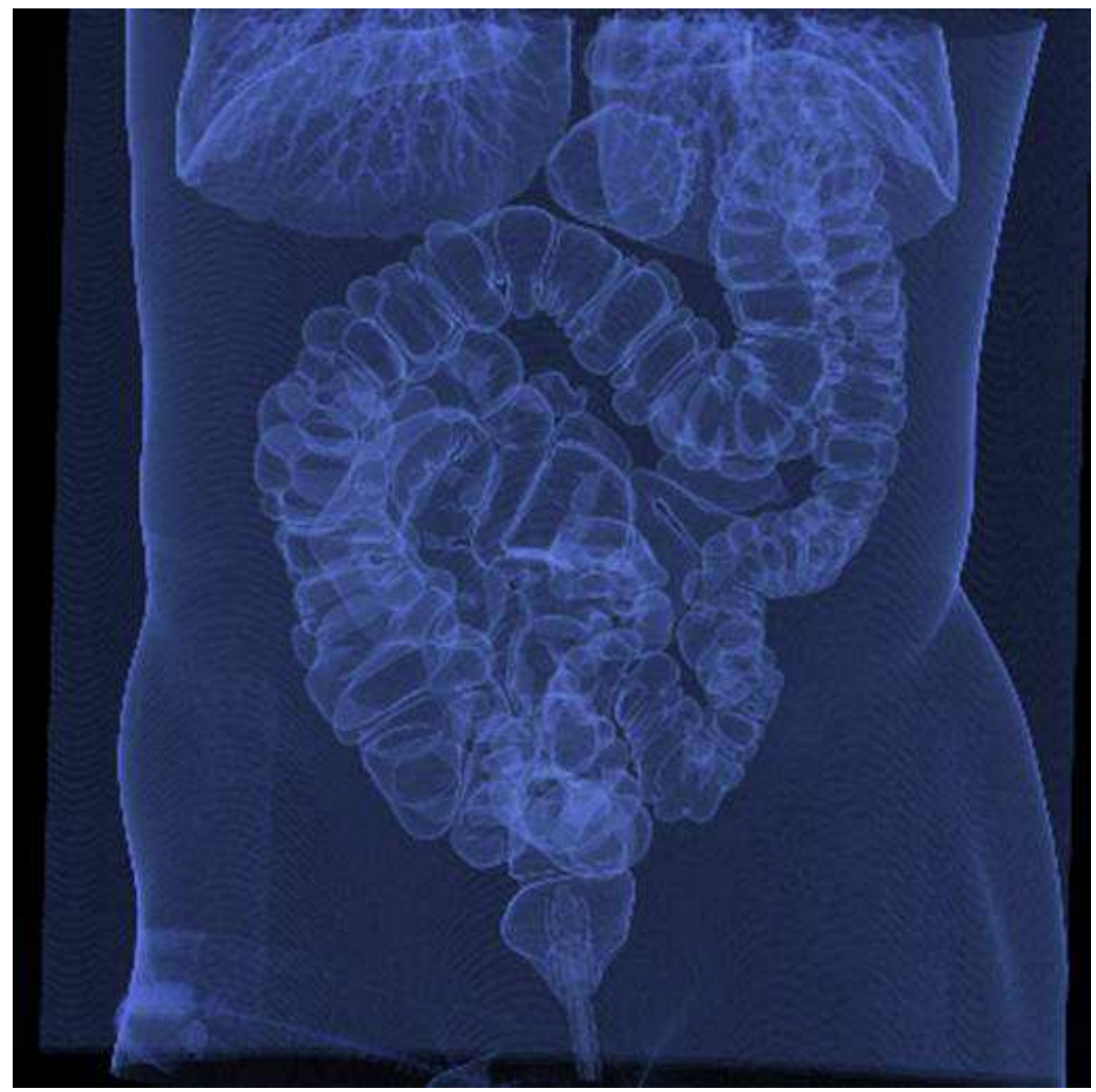

Fig. 1. After the insufflation is performed, a scout image of the abdomen is obtained, to evaluate the need for more insufflation 

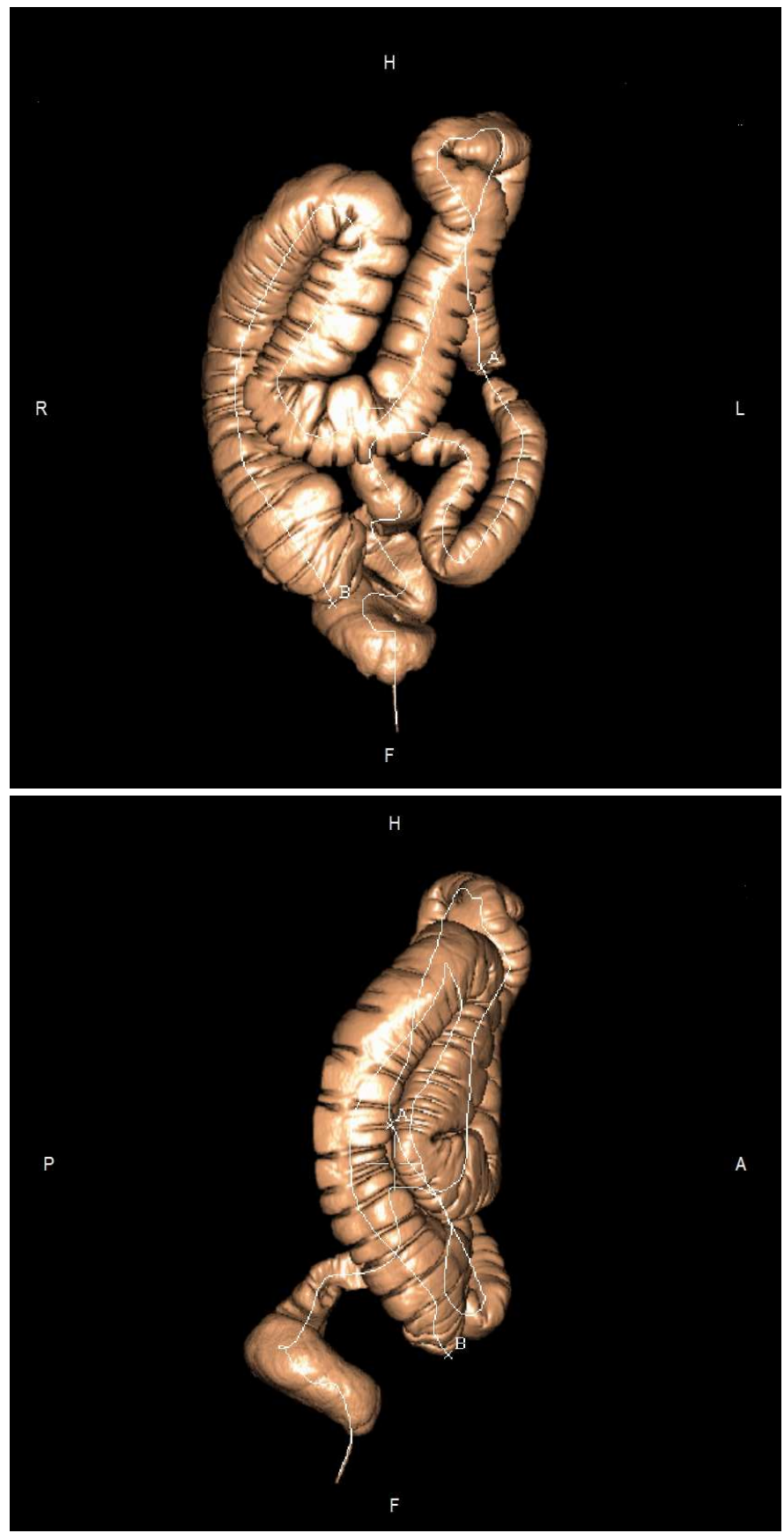

Fig. 2. Virtual colonoscopic pathway view of colon. (H: Head, F:Foot, R:Right, L:Left, A: Anterior, P:Posterior) 


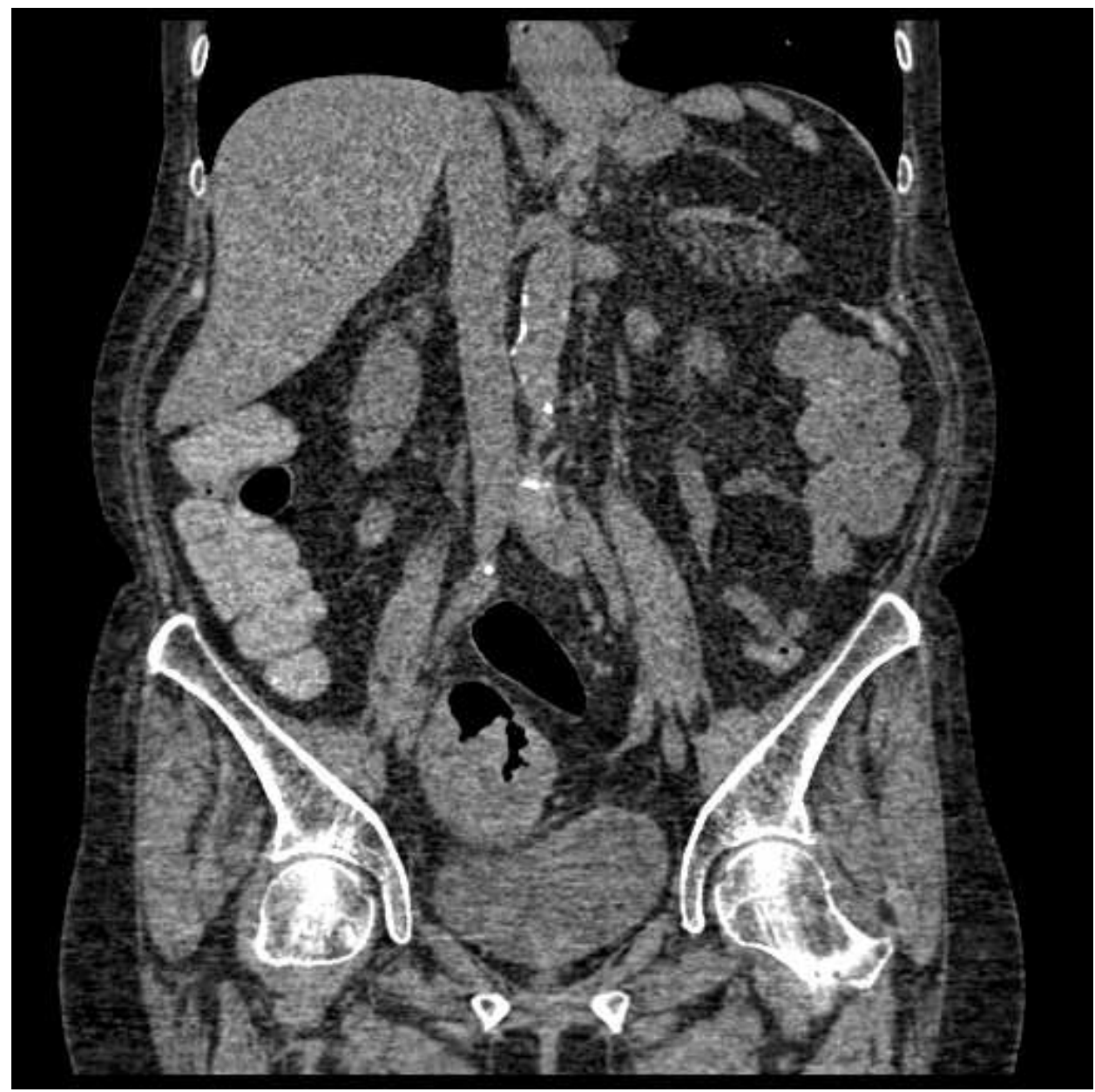

Fig. 3. Extracolonic pathologies can be seen in virtual colonoscopy (sigmoid colon carcinoma)

\section{Advantages and disadvantages of virtual colonoscopy}

Virtual colonoscopy has many advantages such as the evaluation of extracolonic structures and moving inside the colon with a "fly-through" view as if a conventional colonoscopy examination. (Kim et al., 2007; Macari et al., 2011; Pedersen et al., 2003; Pescatore et al., 2000; Pickhardt et al., 2011; Pilch-Kowalczyk et al., 2004; Roberts-Thomson et al., 2008; Sutherland et al., 2011; White et al., 2009)(Fig 3,4). Virtual examinations carry the advantages including being relatively noninvasive, safe, and acceptable by clinicians (Ekci \& Yildirim, 2009; Johnson \& Dackman., 2000; Leksowski el al., 2011; McHugh et al., 2011; Vining, 1996). All these advantages may facilitate the detection of polyps with certain size. (Table 1) Probably, the most important disadvantage of the virtual colonoscopy is that it is only possible to detect the presence of polyp, and that biopsy cannot be performed or polyps cannot be 
removed with this procedure (Byers et al., 1997; Dachman \& Yoshida, 2003; Ignjatovic et al., 2010; Fenlon, 2002; Levin et al., 2003; Pilch-Kowalczyk et al., 2004). (Table 2). Polyps appear as intraluminal nodular filling defects on 3D endoluminal images. Their shape is mostly round or oval, but may also have lobulated features. Most of the polyps are sessile; some of them are pedunculated characterized with a stalk. It is noteworthy to mention that some of the pedunculated polyps may change position among prone and supine images, in this case the presence of the stalk helps to prevent diagnostic confusion with fecal residue (Chang et al., 2011; Ignjatovic et al., 2010; Liedenbaum et al., 2010; Taylor et al., 2003). The differentiation of polyps and fecal residue is one of the most important diagnostic challenges in evaluation of CTC. At this point, combined evaluation of both 2D and 3D images is mandatory. On 3D views, both entities are seen as luminal filling defects, on the other hand fecal residue mostly contain air density foci that can readily be seen on 2D images. Another important clue is the change in position of fecal material among supine and prone images (Ferrucci 2001; Wu et al.,2011; Taylor et al., 2003).
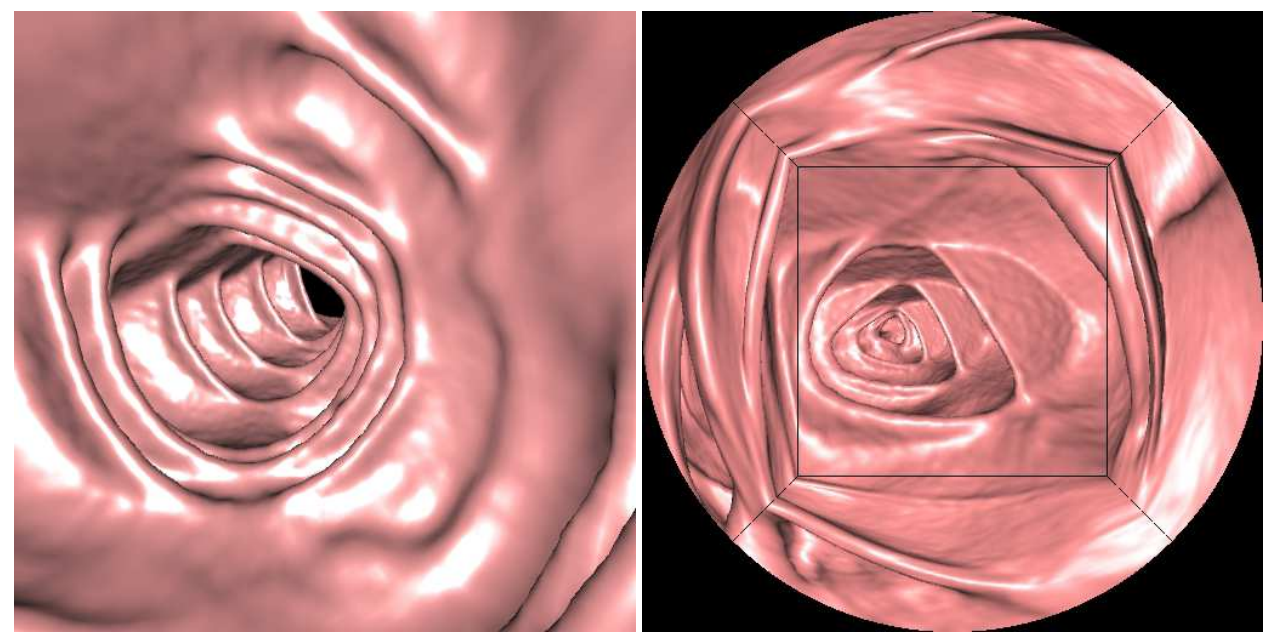

Fig. 4. "Fly-through" view in colon

Diverticula are relatively common findings on CTC, which appear as air-filled sacs on 2D, and as "complete dark ring" on 3D endoluminal images. This "complete dark ring" appearance is important, since polyps different from diverticula are well defined at their free-profile margin only. On the other hand, when diverticula are filled with fecal material, differentiation might be difficult, since they will be seen as polypoid structures bulging to the lumen from the diverticular orifice (Taylor et al., 2003; Ferrucci 2001).

Pseudo lesions observed with virtual colonoscopy are residual fecal material, ileocecal valve, bulbous and irregular interhaustral folds, inadequate colon distention and extrinsic compression defects (Fig 5). Another disadvantage of virtual colonoscopy is the false negative or false positive rates. The most common reasons are inadequate colon preparation, inadequate distention and bulbous haustral fold (Hara et al., 2001; Halligan et al., 2006; Ferrucci, 2001; Roberts-Thomson et al., 2008). Screening in prone or supine position or administration of IV contrast agent might be helpful to avoid confusing polyps with residual fecal material. (Fletcher et al., 1998; Stuart \& Andrea, 2007). Attempts have been made to further increase the accuracy of CTC, with the so-called "tagging" methods. They 
include basically fecal and fluid tagging. In the tagging methods, laxative dose is reduced and the preparation is accompanied with oral contrast material in order to "tag" the possible residual stool and fluid. From the patient point of view, the tagging methods, enabling less laxative dosage, increase patient compliance by reducing the uncomfortable symptoms related to bowel cleansing. It is well known that fluid and fecal tagging improve the diagnostic performance by reducing the number of false-positive and false-negative results. During the tagging process, the ingested bowel contents are marked with contrast and in turn, they are easily differentiated from real lesions. The polyps, as expected, do not absorb the ingested contrast material and remain in their original soft tissue density which make them easily distinguishable from bowel contents that are admixed and coated with contrast (Bielen et al., 2003; Pickhardt, 2007 ). Most of the studies suggest increased diagnostic accuracy of CTC with the use of tagging methods (Dachmann et al., 2007; Liedenbaum et al., 2011; McFarland \& Brink., 1999).

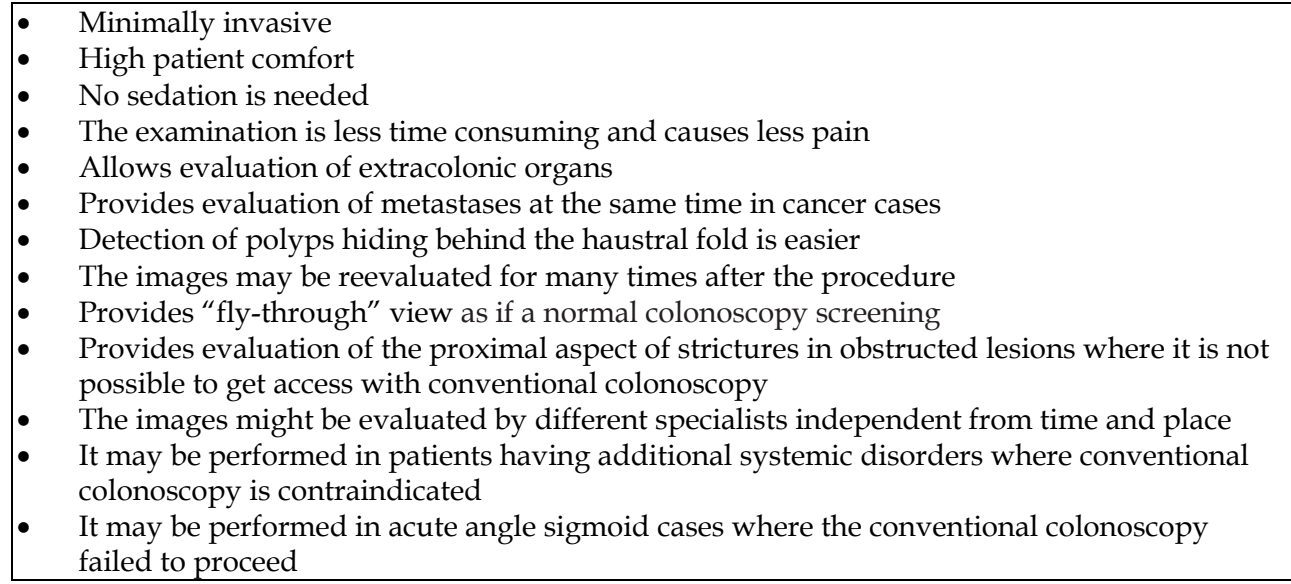

Table 1. Potential advantages of virtual colonoscopy

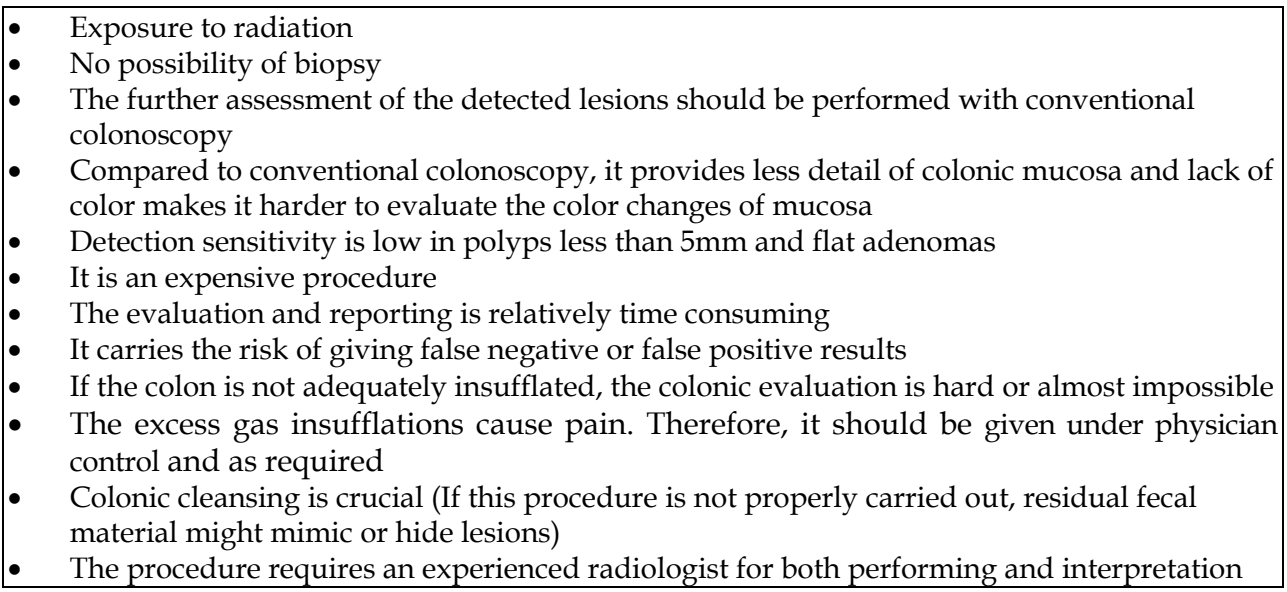

Table 2. Disadvantages of virtual colonoscopy 


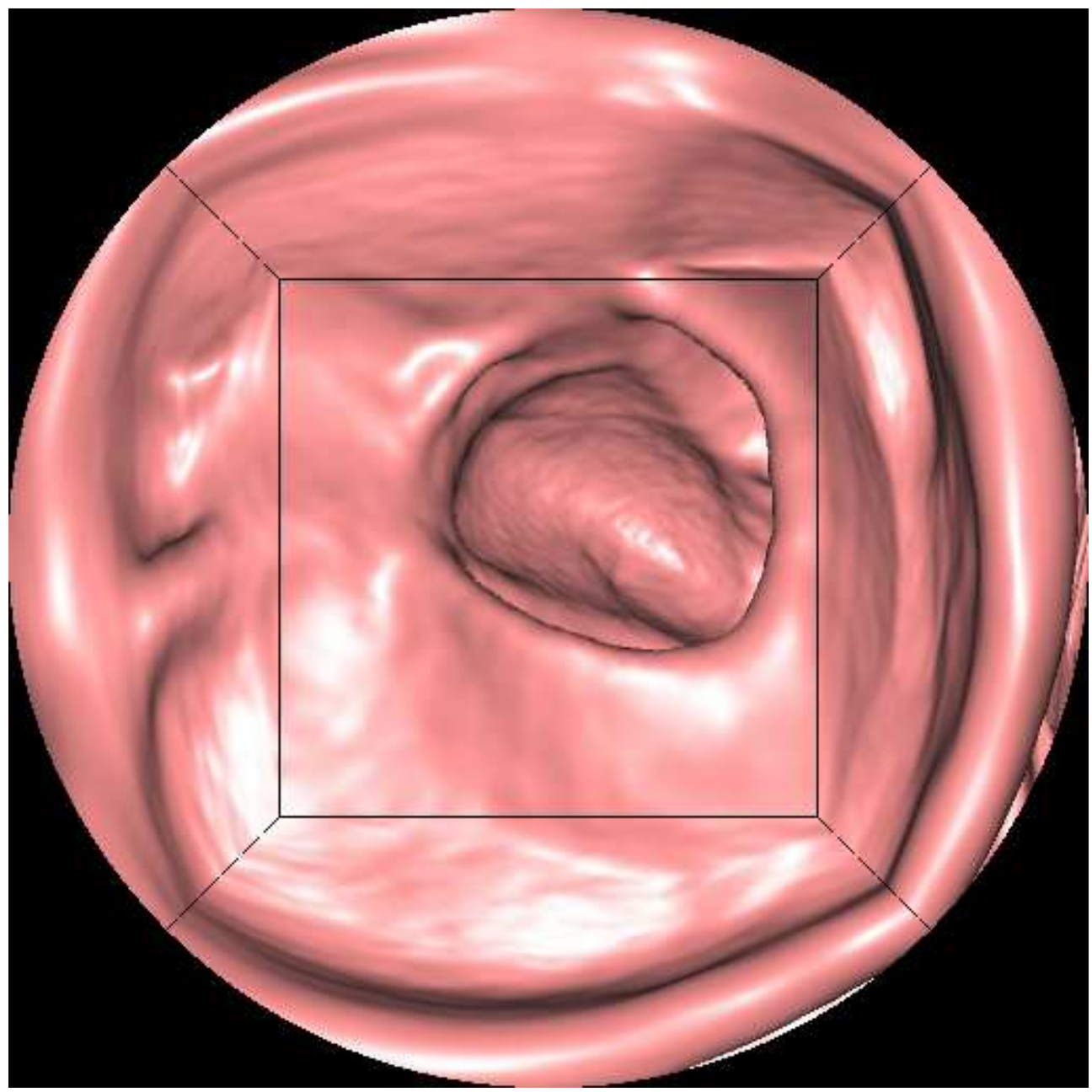

Fig. 5. Residual fecal material

For the "tagging" procedure, only barium, only iodine, or their combination can be used, the latter resulting in both fecal and fluid tagging. The optimal "tagging formula" is still under debate as to which agents to be used in which dosages (Chang et al., 2011; Pickhardt et al., 2003; Pickhardt, 2007).

Another important factor affecting the rate of polyp detection in CTC is the slice thickness. Studies comparing the efficiency of $3 \mathrm{~mm}$ and $5 \mathrm{~mm}$ slices have reported that the image clarity of $5 \mathrm{~mm}$ slices was less than that of $3 \mathrm{~mm}$ slices and that $5 \mathrm{~mm}$ slices were less sensitive to polyps sized less than $5 \mathrm{~mm}$. (Hara et al., 1997; Rogalla et al., 2002). It was concluded that the use of slices less than $3 \mathrm{~mm}$ was beneficial in CTC. (Stuart\&Andrea, 2007). With the technological improvements, this technique yielded images with better resolution, thereby obtaining significantly higher polyp detection rates (Aschoff et al., 2004; Dachman et al., 2007; Vining, 1996) (Fig 6). 

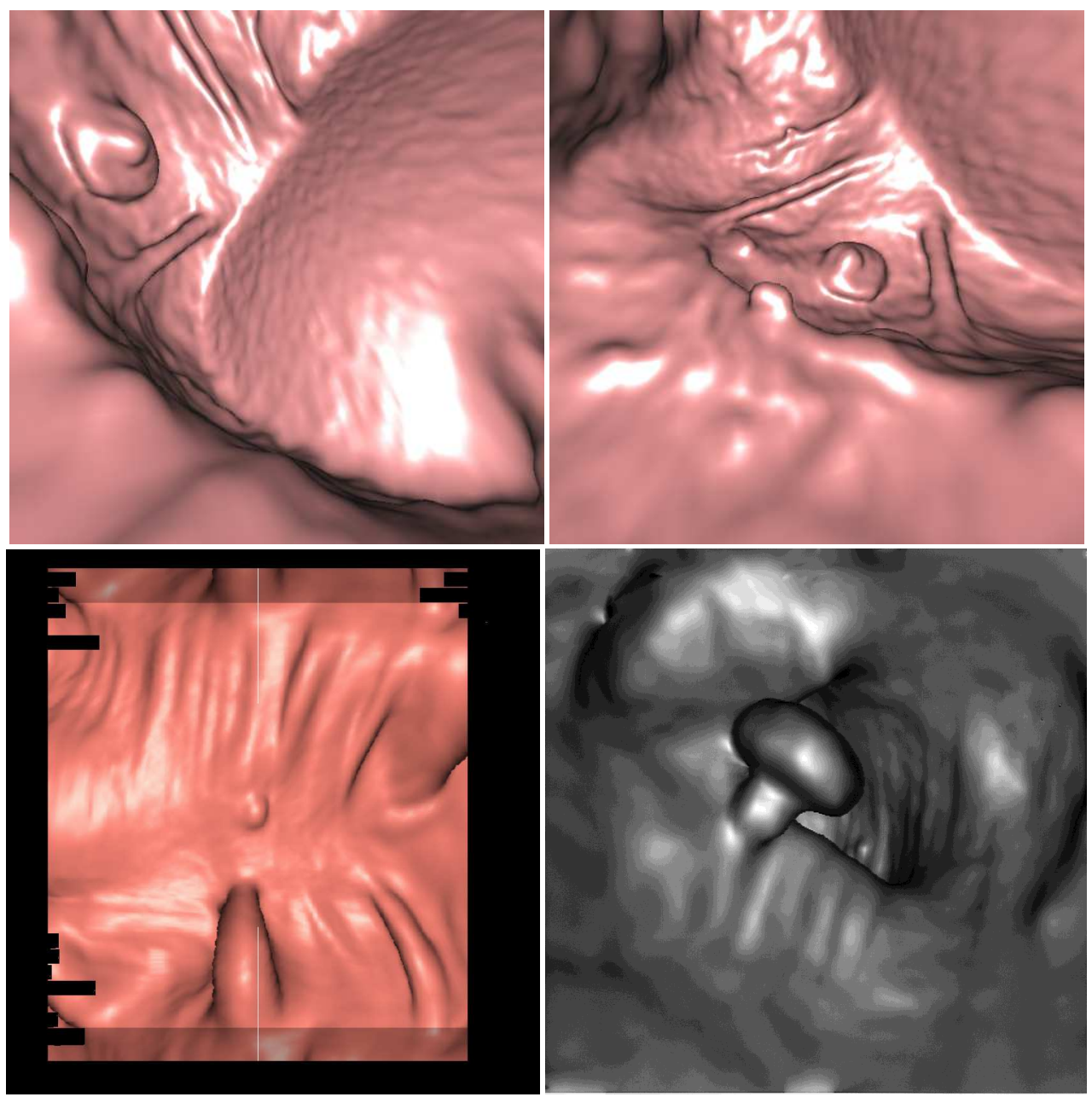

Fig. 6. Colonic polyps' view on 3D CTC images

The modality of choice in the detection of colonic polyps is still fiberoptic colonoscopy. Fiberoptic colonoscopy is the only modality that allows detection and at the same time, excision of the polyps. For adenomatous lesions measuring more than $1 \mathrm{~cm}$, this technique has high sensitivity (> $95 \%$ ) and specificity (100\%). A false negative rate of $6 \%$ has been reported (Dachman\&Yoshida, 2003; Dachman et al., 2007). The sensitivity of virtual colonoscopy in the detection of polyps measuring more than $1 \mathrm{~cm}$ is, $90-94 \%$ (Oto et al., 2003). Studies comparing conventional and virtual colonoscopy have shown that these two modalities have similar sensitivity values for polyps measuring more than $7 \mathrm{~mm}$ (Menardo, 2004), while virtual colonoscopy has limited efficiency for the detection of polyps less than 5 $\mathrm{mm}$ (Aschoff et al., 2004). In another study comparing these two modalities in terms of detection of colonic adenomas measuring more than $6 \mathrm{~mm}$, the sensitivity of virtual 
colonoscopy was reported as $88.7 \%$, and the sensitivity of optic colonoscopy was $92.3 \%$. And in the same study the sensitivity values for lesions measuring more than $10 \mathrm{~mm}$ were reported as $93.8 \%$ and $87.5 \%$, respectively (Pickhardt et al., 2003). Gottlieb (Gottlieb, 2004), evaluated patients who had undergone virtual colonoscopy, followed by optic colonoscopy and the author reported a 10\% false negative rate of optic colonoscopy in the detection of polyps dependent on the operator, whereas lower false negative rates were reported for virtual colonoscopy.

The sensitivity rates of optic and virtual colonoscopy are getting closer to each other, parallel to the technological advances. The varying sensitivity values of virtual colonoscopy for polyps measuring 1-5 mm most probably depend on; the adequacy of bowel cleansing, CT acquisition technique, the administration of intravenous contrast medium, the relation of the lesion with mucosal folds, and experience of the radiologist. Among these issues, experience of the radiologist is very important in terms of high diagnostic performance. There are highly different and variable accuracy values reported among different readers, which in turn needs to be standardized with reader training. Various reports indicate that increased reader education and experience provides better accuracy in terms of CTC evaluation (Burling et al., 2007; Haycock et al., 2010; Philip et al.,2011).

\section{Conclusion}

In conclusion, the size and location of the polyps can be successfully detected by virtual colonoscopy, but it is noteworthy to indicate that conventional colonoscopy is inevitable for pathologic diagnosis. Due to the above-mentioned reasons, we believe that virtual colonoscopy is suitable for screening purposes, and cannot replace the necessity for conventional colonoscopy for definitive diagnosis. However, with technological advances the application of virtual colonoscopy may contribute significantly to the diagnosis of colonic diseases.

\section{References}

Altıparmak E, Orhan S, Erkan P, Engin A. (2001). Colorectal polyps: The Yuiksek Ihtisas experience. Turk J Gastroenterol, 12, pp. 49-52.

Anderson ML, Heigh RI, McCoy GA, Parent K, Muhm JR, McKee GS, Eversman WG, Collins JM. (1992). Accuracy of assessment of the extent of examination by experienced colonoscopists. Gastrointest Endosc, 38, pp. 560-3.

Aschoff, AJ, Juchems MS, Weber CK, Brambs HJ. (2004). CT colonography "virtual colonoscopy" a current review. Z Gastroenterol. 42, pp.1199-205.

Bakir B, Yekeler E, Tunaci M, Tunaci A, Acunaş B, Acunaş G. (2004). Diagnostic efficiency of multislice computed tomography colonography in the detection of colorectal tumors: comparison with conventional colonography. Tani Girisim Radyol, 10, pp. 218-29. Turkish.

Bielen D, Thomeer M, Vanbeckevoort D, Kiss G, Maes F, Marchal G, Rutgeerts P. (2003). Dry preparation for virtual CT colonography with fecal tagging using water-soluble contrast medium: initial results. Eur Radiol, 2003,13, pp. 453-8.

Burling D, Moore A, Taylor S, La Porte S, Marshall M. (2007). Virtual colonoscopy training and accreditation: a national survey of radiologist experience and attitudes in the UK. Clin Radiol, 62 pp.651-659 
Byers T, Levin B, Rothenberger D, Dodd GD, Smith RA. (1997)American Cancer Society guidelines for screening and surveillance for early detection of colorectal polyps and cancer: update 1997. CA Cancer J Clin ,47, pp.154-60.

Chang KJ, Rekhi SS Jr, Anderson SW, Soto JA. (2011). Fluid tagging for CT colonography: effectiveness of a 2-hour iodinated oral preparation after incomplete optical colonoscopy. J Comput Assist Tomogr. 2011, 35 pp.91-5.

Chao A, Connell CJ, Cocckinides V, Jacobs EJ, Calle EE, Thun MJ. (2004). Underuse of screening sigmoidoscopy and colonoscopy in a large cohort of US adults. Am J Public Health, 94, pp. 1775- 81.

Colucci PM, Yale SH, Rall CJ.(2003). Colorectal polyps. Clin Med Res, 1, pp. 261-2.

Consolo P, Luigiano C, Strangio G, Scaffidi MG, Giacobbe G, Di Giuseppe G, Zirilli A, Familiari L. (2008). Efficacy risk factors and complications of endoscopic polypectomy: Ten year experience at a single center. World J Gastroenterol, 14, pp. 2364-9.

Dachman AH, Lefere P, Gryspeerdt S, Morin M. (2007). CT colonography: visualization methods, interpretation, and pitfalls. Radiol Clin North Am, 45, pp. 347-59.

Dachman, AH. Yoshida H. (2003). Virtual colonoscopy: past, present,and future. Radiol Clin $N A m, 41$, pp.377-393

Detsky AS. (2001). Screening for colon cancer: can we afford colonoscopy? N Engl J Med, 345, pp. 607-8.

Eddy DM. (1990). Screening for colorectal cancer. Ann Intern Med, 113, pp. 373-84.

Ekci B, Yildirim D. (2009). Virtual Angioscopy in the Assessment of Vascular Invasion: Is it More Reliable than CT Angiography; Yeditepe Medical Journal, 9, pp. 142-150

Erdem L, Akbayır N, Yıldırım S, Köksal HM, Yenice N, Guiltekin OS, Sakiz D, Peker O. (2005). Predictive value of morphologic characteristics in rectosigmoid adenomatous polyps for the probability of synchronous polyps or cancer in the proximal colon. Turk J Gastroenterol , 16, pp. 207-11.

Fenlon HM. (2002). Virtual colonscopy. British Journal of Surgery, 89, pp. 1-3

Ferrucci JT. (2001). Colon Cancer Screening with Virtual Colonoscopy: Promise, Polyps, Politics. AJR, 177, pp. 975-988

Fletcher JG, Jhonson CD, MacCarthy RL. (1998). CT colonography: overcoming the problems of collapse and colonic fluid. Radiology, 209, pp. 96.

Gottlieb S. (2004) Routine colonoscopies miss more than 10\% of polyps. BMJ 329, pp.701

Halligan S, Park SH, Ha HK. (2006). Causes of false negative findings at CT colonography. Radiology, 238, pp. 1075-6

Hara AK, Johnson CD, McCarty RL, Welch TJ, McCollough CH, Harmsen WS. (2001). CT colonography: single versus multi-detector row imaging. Radiology, 219, pp. 461-5

Hara AK, Johnson CD, Reed JE, Ahlquist DA, Nelson H, Ehman RL, Harmsen WS. (1997). Reducing data size and radiation dose for CT colonography. AJR Am J Roentgenol, 168, pp. 1181-4.

Hawk ET, Levin B. (2005). Colorectal cancer prevention. J Clin Oncol , 23, pp. 378-91.

Haycock A, Burling D, Wylie P, Muckian J, Ilangovan R, Thomas-Gibson S. (2010). CT colonography training for radiographers--a formal evaluation. Clin Radiol. 65 pp.997-1004.

Hock D, Ouhadi R, Materne R, Mancini I, Nchimi A. (2011). Screening for colorectal cancer in asymptomatic average risk patients: role of imaging. Acta Gastroenterol Belg, 74 pp.70-6.

Hounsfield GN. (1973). Computerized transverse axial scanning (tomography): Part 1. Description of the system. Br J Radiol, 46, pp. 1016-22. 
Ignjatovic A, Burling D, Ilangovan R, Clark SK, Taylor SA, East JE, Saunders BP. (2010). Flat colon polyps: what should radiologists know? Clin Radiol 65, pp.958-66.

Jemal A, Thomas A, Murray T. (2002). Cancer Statistics, 2002. CA Cancer J Clin, 252, pp. 23-47.

Johnson CD, Dackman AH. (2000). CT colonography: the text colon screening examination. Radiology, 216, pp. 331-41.

Kim JH, Kim WH, Kim TI, Kim NK, Lee KY, Kim MJ, Kim KW. (2007). Incomplete Colonoscopy in Patients with Occlusive Colorectal Cancer: Usefulness of CT Colonography According to Tumor Location. Yonsei Med J, 48, pp. $934-41$.

Labianca R, Merelli B. (2010). Screening and diagnosis for colorectal cancer: present and future. Tumori, 96 pp.889-901

Leksowski K, Rudzinska M, Rudzinski J. (2011). Computed tomographic colonography in preoperative evaluation of colorectal tumors: a prospective study. Surg Endosc [Epub ahead of print] DOI 10.1007/s00464-010-1566-0

Levin B, Brooks D, Smith RA, Stone A. (2003). Emerging technologies in screening for colorectal cancer: CT colonography, immunochemical fecal occult blood tests, and stool screening using molecular markers. CA Cancer J Clin, 53, pp.44-55

Liedenbaum MH, Denters MJ, Zijta FM, van Ravesteijn VF, Bipat S, Vos FM, Dekker E, Stoker J. (2010). Reducing the oral contrast dose in CT colonography: evaluation of faecal tagging quality and patient acceptance. Clin Radiol, 66 pp.30-7.

Macari M, Nevsky G, Bonavita J, Kim DC, Megibow AJ, Babb J. (2011). CT Colonography in Senior versus Nonsenior Patients: Extracolonic Findings, Recommendations for Additional Imaging, and Polyp Prevalence. Radiology, 259 pp.767-74

Mang T, Graser A, Schima W, Maier A. (2007). CT colonography: techniques, indications, findings. Eur J Radiol, 61, pp.388-99.

McFarland EG, Brink JA. (1999). Helical CT colonography (virtual colonoscopy): the challenge that exists between advancing technology and generalizability. AJR Am J Roentgenol, 173, pp.549-59.

McHugh M, Osei-Anto A, Klabunde CN, Galen BA. (2011). Adoption of CT colonography by US hospitals. J Am Coll Radiol, 8 pp.169-74

Menardo, G. (2004) Sensitivity of diagnostic examinations for colorectal polyps. Tech coloproctol, 8 Suppl 2, pp.273-5.

Netzer P, Forster C, Biral R, Ruchti C, Neuweiler J, Stauffer E, Schönegg R, Maurer C, Hüsler J, Halter F, Schmassmann A. (1998). Risk factor of endoscopically removed malignant colorectal polyps. Gut, 43, pp. 669-74.

Oto A, Gebelek V, Oguz BS, Sivri B, Deger A, Akhan O, Besim A. (2003). CT attenuation of colorectal polypoid lesions: evaluation of contrast enhancement in CT colonography. Eur Radiol, 13, pp.1657-63

Pedersen BG, Rosenkilde M, Christiansen TEM, Laurberg S. (2003). Extracolonic findings at computed tomography colonography are a challenge. Gut, 52, pp.1744-7

Pescatore P, Glücker T, Delarive J, Meuli R, Pantoflickova D, Duvoisin B, Schnyder P, Blum AL, Dorta G. (2000). Diagnostic accuracy and interobserver agreement of CT colonography (virtual colonoscopy). Gut, 47, pp.126-30

Pickhardt PJ, Hassan C, Halligan S, Marmo R. (2011). Colorectal Cancer: CT Colonography and Colonoscopy for Detection--Systematic Review and Meta-Analysis. Radiology, 259 pp.393-405.

Pickhardt PJ. (2007). Screening CT colonography: how I do it. AJR Am J Roentgenol, 189, pp. 290-8. Pickhardt PJ. Choi JR, Hwang I, Butler JA, Puckett ML, Hildebrandt HA, Wong RK, Nugent PA, Mysliwiec PA, Schindler WR. (2003). Computed tomographic virtual 
colonoscopy to screen for colorectal neoplasia in asymptomatic adults. $N$ Engl J Med, 349, pp. 2191-200.

Pilch-Kowalczyk J, Konopka M, Gibinska J, Zymon-Zagorska A, Hartel M, Sallam B, Baron J. (2004). Extracolonic findings at CT colonography additional advantage of the method. Med Sci Monit, 10, pp. 22-25

Roberts-Thomson IC, Tucker GR, Hewett PJ, Cheung P, Sebben PA, Win Khoo EE, Marker JD, Clapton WK. (2008). Single-center study comparing computed tomography colonography with conventional colonoscopy. World J Gastroenterol, 14, pp. 469-73

Rogalla P,Meiri N, Hamm B, Rückert J. (2002). Multislice CT Colonography. Eur J Radiol, 36, pp. 81-5.

Stuart A, Andrea L. (2007). ESGAR: Consensus statement on CT colonography. Eur Radiol, 17, pp. 575-9.

Su MY, Ho YP, Hsu CM, Chiu CT, Chen PC, Lien JM, Tung SY, Wu CS. (2005). How can colorectal neoplasms be treated during colonoscopy? World J Gastroenterol , 11, pp. 2806-10.

Sutherland T, Coyle E, Lee WK, Lui B. (2011). Diagnosing colorectal polyps and masses - the use of CT colonography. Aust Fam Physician, 40 pp.117-20.

Taylor SA, Halligan S, Bartram CI. (2003). CT colonography: methods, pathology and pitfalls. Clin Radiol, 58, pp.179-90.

Tolan DJ, Armstrong EM, Burling D, Taylor SA. (2007). Optimization of CT colonography technique: a practical guide. Clin Radiol, 62, pp.819-27.

Towler BP, Irwing L, Glasziou P, Kewenter J, Weller D, Silagy C. (1998). A systematic review of the effects of screening for colorectal cancer using the feacal occult blood test, hemoccult. BMJ, 317, pp. 559-65.

Van Dam J. (1995). Prevention of colorectal cancer by endoscopic polypectomy. Ann Int Med ,123, pp. 949-50.

Vining DJ. (1996). Virtual endoscopy: is it reality? Radiology, 200, pp. 30-1.

Waye JD, Lewis BS, Yessayan S. (1992). Colonoscopy: a prospective report of complications. J Clin Gastroenterol, 15, pp. 347-51.

White TJ, Avery GR, Kenan N, Syed AM, Hartley JE, Monson JRT. (2009). Virtual Colonoscopy versus Conventional colonoscopy in patients at high risk of colorectal cancer- a prospective trial of 150 patients. Colorectal Dis, 11, pp.138-45

Wu XW, Liu B, Wang WQ, Xu JM. (2011). CT virtual colonoscopy in displaying excavated colon lesions. Clin Imaging, 35 pp.198-202.

Yamaji Y, Mitsushima T, Ikuma H, Watabe H, Okamoto M, Kawabe T, Wada R, Doi H, Omata M. (2004). Incidence and recurrence rates of colorectal adenomas estimated by annually repeated colonoscopies on asymptomatic Japanese. Gut, 53, pp. 568-72. 


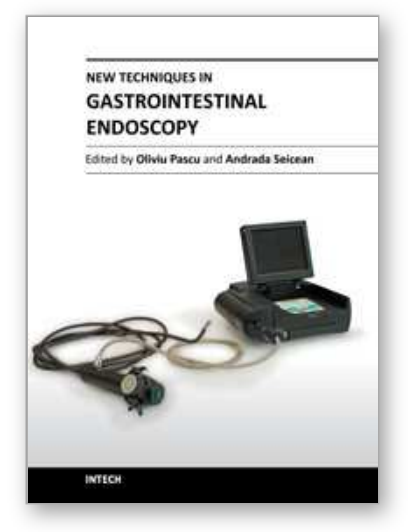

\author{
New Techniques in Gastrointestinal Endoscopy \\ Edited by Prof. Oliviu Pascu
}

ISBN 978-953-307-777-2

Hard cover, 310 pages

Publisher InTech

Published online 30, September, 2011

Published in print edition September, 2011

As result of progress, endoscopy has became more complex, using more sophisticated devices and has claimed a special form. In this moment, the gastroenterologist performing endoscopy has to be an expert in macroscopic view of the lesions in the gut, with good skills for using standard endoscopes, with good experience in ultrasound (for performing endoscopic ultrasound), with pathology experience for confocal examination. It is compulsory to get experience and to have patience and attention for the follow-up of thousands of images transmitted during capsule endoscopy or to have knowledge in physics necessary for autofluorescence imaging endoscopy. Therefore, the idea of an endoscopist has changed. Examinations mentioned need a special formation, a superior level of instruction, accessible to those who have already gained enough experience in basic diagnostic endoscopy. This is the reason for what these new issues of endoscopy are presented in this book of New techniques in Gastrointestinal Endoscopy.

\title{
How to reference
}

In order to correctly reference this scholarly work, feel free to copy and paste the following:

Baki Ekçi, Bengi Gürses and Düzgün Yıldırım (2011). Non-Invasive Endoscopy Technique - Virtual Colonoscopy, New Techniques in Gastrointestinal Endoscopy, Prof. Oliviu Pascu (Ed.), ISBN: 978-953-307777-2, InTech, Available from: http://www.intechopen.com/books/new-techniques-in-gastrointestinalendoscopy/non-invasive-endoscopy-technique-virtual-colonoscopy

\section{INTECH}

open science | open minds

\author{
InTech Europe \\ University Campus STeP Ri \\ Slavka Krautzeka 83/A \\ 51000 Rijeka, Croatia \\ Phone: +385 (51) 770447 \\ Fax: +385 (51) 686166 \\ www.intechopen.com
}

\author{
InTech China \\ Unit 405, Office Block, Hotel Equatorial Shanghai \\ No.65, Yan An Road (West), Shanghai, 200040, China \\ 中国上海市延安西路65号上海国际贵都大饭店办公楼 405 单元 \\ Phone: +86-21-62489820 \\ Fax: $+86-21-62489821$
}


(C) 2011 The Author(s). Licensee IntechOpen. This chapter is distributed under the terms of the Creative Commons Attribution-NonCommercialShareAlike-3.0 License, which permits use, distribution and reproduction for non-commercial purposes, provided the original is properly cited and derivative works building on this content are distributed under the same license. 